\title{
Gold nanocrystals with variable index facets as highly effective cathode catalysts for lithium-oxygen batteries
}

\author{
Dawei $\mathrm{Su}^{1,2}$, Shixue Dou ${ }^{2}$ and Guoxiu Wang ${ }^{1}$ \\ Cathode catalysts are the key factor in improving the electrochemical performance of lithium-oxygen $\left(\mathrm{Li}-\mathrm{O}_{2}\right)$ batteries via their \\ promotion of the oxygen reduction and oxygen evolution reactions (ORR and OER). Generally, the catalytic performance of \\ nanocrystals (NCs) toward ORR and OER depends on both composition and shape. Herein, we report the synthesis of polyhedral \\ Au NCs enclosed by a variety of index facets: cubic gold (Au) NCs enclosed by $\{100\}$ facets; truncated octahedral Au NCs \\ enclosed by $\{100\}$ and $\{110\}$ facets; and trisoctahedral (TOH) Au NCs enclosed by 24 high-index $\{441\}$ facets, as effective \\ cathode catalysts for $\mathrm{Li}-\mathrm{O}_{2}$ batteries. All Au NCs can significantly reduce the charge potential and have high reversible \\ capacities. In particular, TOH Au NC catalysts demonstrated the lowest charge-discharge overpotential and the highest capacity \\ of $\sim 20298 \mathrm{~mA} \mathrm{~h} \mathrm{~g}^{-1}$. The correlation between the different Au NC crystal planes and their electrochemical catalytic \\ performances was revealed: high-index facets exhibit much higher catalytic activity than the low-index planes, as the high-index \\ planes have a high surface energy because of their large density of atomic steps, ledges and kinks, which can provide a high \\ density of reactive sites for catalytic reactions.
}

NPG Asia Materials (2015) 7, e155; doi:10.1038/am.2014.130; published online 16 January 2015

\section{INTRODUCTION}

The lithium-oxygen $\left(\mathrm{Li}-\mathrm{O}_{2}\right)$ battery is currently the subject of much scientific investigation as the power source for electric vehicles because of its high energy density $\left(2-3 \mathrm{kWh} \mathrm{kg}^{-1}\right) .{ }^{1}$ Unlike the intercalation reactions of Li-ion batteries, ${ }^{2}$ the reaction mechanism in a $\mathrm{Li}-\mathrm{O}_{2}$ cell involves an oxygen reduction reaction (ORR) in the discharge process and an oxygen evolution reaction (OER) in the charge process, during which, molecular $\mathrm{O}_{2}$ reacts reversibly with $\mathrm{Li}^{+}$ions $\left(\mathrm{Li}^{+}+\mathrm{O}_{2}+2 \mathrm{e}^{-} \leftrightarrow\right.$ $\mathrm{Li}_{2} \mathrm{O}_{2}$, with an equilibrium voltage of $2.96 \mathrm{~V}$ vs. Li). ${ }^{3}$ The performance of $\mathrm{Li}-\mathrm{O}_{2}$ batteries is constrained by several serious issues, such as poor cycling stability, ${ }^{4}$ electrolyte instability, ${ }^{5}$ low-rate capability ${ }^{6}$ and low round-trip efficiencies, ${ }^{1}$ mainly resulting from the high overpotential on charge. ${ }^{7}$ Recently, it was found that the catalyst and the proper non-aqueous electrolyte are the key factors to address these problems. ${ }^{8}$ Therefore, various electrocatalysts, including carbons, metal oxides, metal nitrides and precious metals have been examined as the cathode catalysts in $\mathrm{Li}-\mathrm{O}_{2}$ cells to lower the charge overpotential. ${ }^{9}$ It was reported that the use of catalysts can decrease the charge potential to $\sim 3.8$ from $\sim 4.2 \mathrm{~V} .{ }^{10}$ It has been shown, however, that the theoretical overcharge potential for a $\mathrm{Li}_{2} \mathrm{O}_{2}$ film is only $0.2 \mathrm{~V}$, if there are no limitations on charge transport through $\mathrm{Li}_{2} \mathrm{O}_{2}$ to the $\mathrm{Li}_{2} \mathrm{O}_{2}$-electrolyte interface. ${ }^{11}$ Therefore, it is possible to further lower the charge potential. Moreover, a fundamental understanding of how to resolve the high overpotential on charge and the mechanisms of both ORR and OER, respectively in non-aqueous electrolytes are important for developing $\mathrm{Li}-\mathrm{O}_{2}$ batteries.
Anisotropy is one of the basic properties of crystals, and different facets of a single crystal may exhibit different physical and chemical properties. In the past decade, control of the shape of metallic nanostructures has attracted intensive interests, because it may provide an effective route for tuning the catalytic properties of metals. ${ }^{12}$ It has been widely recognized that high-index facets, having a high density of atomic steps, ledges, kinks and dangling bonds, usually exhibit much higher chemical-reaction activities. ${ }^{13,14}$ For example, a single-crystal Pt tetrahexahedral nanocrystal (NC) is enclosed by 24 high-index facets such as $\{730\},\{210\}$ and/or $\{520\}$ surfaces. These NCs exhibited much enhanced (up to $400 \%$ ) catalytic activity compared with equivalent commercial Pt catalysts toward electro-oxidation of small organic fuels. ${ }^{14}$ Therefore, for the Li-O $\mathrm{O}_{2}$ battery, synthesis of noble metal NCs bounded by high-index facets could have the potential of significantly improve the catalytic performance toward ORR and OER.

In 2012, it was reported that porous gold foil is a good catalyst for a reversible and higher-rate $\mathrm{Li}-\mathrm{O}_{2}$ battery with a high reversibility. ${ }^{15}$ Herein, we report the controllable synthesis of polyhedral Au NCs with different shapes and crystal planes, including trisoctahedral (TOH) Au NCs enclosed by 24 high-index $\{441\}$ facets, and their catalytic properties in $\mathrm{Li}-\mathrm{O}_{2}$ batteries. Electrochemical testing shows that all Au NCs can significantly reduce the charge potential and have high reversible capacities. In particular, the electrodes with $\mathrm{TOH} \mathrm{Au}$ NC catalysts demonstrated the lowest charge-discharge overpotential, and the highest reversible capacity of about $20298 \mathrm{~mA} \mathrm{~h} \mathrm{~g}^{-1}$. It was found that the essential factor in promoting the ORR and OER in the

${ }^{1}$ Centre for Clean Entergy Technology, School of Chemistry and Forensic Science, University of Technology Sydney, Broadway, Sydney, NSW, Australia and ${ }^{2}$ Institute for Superconducting and Electronic Materials, University of Wollongong, Wollongong, NSW, Australia

Correspondence: Professor G Wang or Professor S Dou, School of Chemistry and Forensic Science, University of Technology Sydney, Broadway, Sydney, NSW 2007, Australia. E-mail: Guoxiu.Wang@uts.edu.au or shi@uow.edu.au

Received 14 July 2014; revised 2 October 2014; accepted 25 November 2014 
$\mathrm{Li}-\mathrm{O}_{2}$ battery is the surface crystal planes of the Au NCs. The ORR and OER are crystal plane-dependent processes. Furthermore, the correlation between the different Au NC crystal planes and their electrochemical catalytic performance was revealed via density function theory calculations and experimental investigations: high-index facets $(\{441\})$ exhibit much higher catalytic activity than low-index planes $(\{111\}$ and $\{100\})$, because of their high surface energy, which can provide a high density of reactive sites for catalytic reactions.

\section{EXPERIMENTAL PROCEDURE}

\section{Synthesis and method}

Materials. Hydrogen tetrachloroaurate (III) hydrate $\left(\mathrm{HAuCl}_{4} \cdot \mathrm{xH}_{2} \mathrm{O}\right.$, SigmaAldrich, Castle Hill, NSW, Australia, $\sim 50 \% \mathrm{Au}$ ), hexadecyltrimethylammonium chloride (CTAC, Sigma-Aldrich $\geqslant 98 \%$ ), hexadecyltrimethylammonium bromide (CTAB, Sigma-Aldrich $\geqslant 99 \%)$, sodium borohydride $\left(\mathrm{NaBH}_{4}\right.$, SigmaAldrich 99.99\%) and L-ascorbic acid (Sigma-Aldrich $\geqslant 99 \%$ ) were used as received.

Synthesis. The polyhedral Au NCs were prepared following a seed-mediated synthesis method in aqueous solutions. ${ }^{16}$ In a typical synthesis, $87.5 \mu \mathrm{l}$ of $20 \mathrm{~mm}$ $\mathrm{HAuCl}_{4}$ solution was added to $7 \mathrm{ml}$ of $75 \mathrm{~mm}$ CTAB solution and then $0.6 \mathrm{ml}$ of $10 \mathrm{mM} \mathrm{NaBH}_{4}$ solution was injected into the mixture. After vigorous shaking to form a brown seed solution, the solution was set aside for another $2 \mathrm{~h}$ to decompose the excess $\mathrm{NaBH}_{4}$. The seed solution was then diluted 100-fold with distilled water for further use. A seed growth solution was prepared by adding $25 \mu \mathrm{l}$ of $20 \mathrm{mM} \mathrm{HAuCl}_{4}$ solution and $0.387 \mathrm{ml}$ of $38.8 \mathrm{~mm}$ ascorbic acid into $12.1 \mathrm{ml}$ of $16.5 \mathrm{~mm}$ CTAB solution. Then, $0.15 \mathrm{ml}$ of the 100 -fold diluted seed solution was added, and the mixture was left undisturbed overnight until the color of the solution changed to pink, indicating the growth of the $\mathrm{Au}$ NC seeds.

Cubic Au NCs were prepared by adding $0.125 \mathrm{ml}$ of $20 \mathrm{mM} \mathrm{HAuCl}_{4}$ solution and $3.06 \mathrm{ml}$ of $38.8 \mathrm{~mm}$ ascorbic acid solution to $9 \mathrm{ml}$ of $22 \mathrm{~mm}$ CTAB solution. Thereafter, $6.5 \mathrm{ml}$ of the Au NC seed solution was added, and the mixture was left undisturbed overnight.

For the preparation of truncated octahedral (T-OCT) Au NCs, $1.33 \mathrm{ml}$ of the $\mathrm{Au}$ NC seed solution was added to $12.5 \mathrm{ml}$ of a mixture containing $16 \mathrm{~mm}$ CTAB, $0.04 \mathrm{~mm} \mathrm{HAuCl}_{4}$ and $1.2 \mathrm{~mm}$ ascorbic acid. The solution was left undisturbed overnight.

The TOH Au NCs were prepared in a similar manner to the cubic Au NCs except for the substitution of CTAC for CTAB at the same concentration.

\section{Structural and physical characterization}

The crystal structure and phase of the as-prepared materials were characterized by X-ray diffraction (XRD, Siemens D5000, Aubrey, TX, USA) using $\mathrm{Cu} \mathrm{K}_{\alpha}$ radiation. The morphology was analyzed by field emission scanning electron microscopy (FESEM, Zeiss Supra 55VP, Jena, Germany). The details of the structure were further characterized by transmission electron microscopy (TEM) and high-resolution TEM (HRTEM, JEOL JEM-2011, Tokyo, Japan). Selected area electron diffraction (SAED) patterns were recorded by a Gatan charge-coupled device camera in a digital format. Atom resolved HRTEM images were obtained by high-angle annular dark field scanning TEM (HAADF-STEM, JEOL JEM-ARM200F). The optical images were collected with a Canon EOS 660D camera. Raman spectra were measured using a Renishaw inVia Raman spectrometer system (New Mills, Wotton-under-Edge, Gloucestershire, UK) equipped with a Leica DMLB microscope (Wetzlar, Germany) and a $17 \mathrm{~mW}$ at $633 \mathrm{~nm}$ Renishaw helium neon laser source. Fourier-transform infrared (FTIR) spectra were recorded on a Nicolet Magna 6700 FT-IR spectrometer (Thermo Fisher, Scoresby, VIC, Australia) with 0.9 $\mathrm{cm}^{-1}$ standard optical resolution by using a $\mathrm{KBr}$ beam splitter.

\section{Electrochemical testing}

Swagelok-type cells were designed to investigate the charge and discharge properties and the cyclability in $\mathrm{Li}-\mathrm{O}_{2}$ batteries, which consists of a stainless steel cylinder plunger to support a $\mathrm{Li}$ foil anode (thickness: $3 \mathrm{~mm}$, diameter: $15 \mathrm{~mm}$ ) and a special stainless steel tube to allow oxygen access to the back side of the cathode. The cathode electrodes were prepared as follows: catalyst slurry was first prepared by mixing the as-prepared catalysts ( $90 \mathrm{wt} . \%$ ) with poly (tetrafluoroethylene) (10 wt.\%) in isopropanol. The mixture was then coated on a glass fiber separator. The cathode film was punched into discs having a diameter of $14 \mathrm{~mm}$ and dried at $110^{\circ} \mathrm{C}$ in a vacuum oven for $12 \mathrm{~h}$. The typical loading of the air electrode was $\sim 1 \mathrm{mg}$ carbon per $\mathrm{cm}^{2}$. The load mass of each electrode is $\sim 1.6 \mathrm{mg}$, and the corresponding load mass of Au NCs catalyst is $\sim 0.64 \mathrm{mg}$, calculated based on the weight percentage of Au NCs in the electrode ( $40 \mathrm{wt} . \%$, as determined by the thermogravimetric analysis). The cathode was placed on the separator, and a thin open 316 stainless steel mesh was placed on top to act as a current collector. The entire cell was gas-tight except for the stainless steel mesh window, which exposed the porous cathode to the $\mathrm{O}_{2}$ atmosphere. The $\mathrm{Li}-\mathrm{O}_{2}$ cells were assembled in an Ar-filled glove box (Unilab, MBRAUN, Garching, Germany) with water and oxygen levels $<0.1 \mathrm{p}$. p.m. A glass microfiber filter (Whatman, diameter: $21 \mathrm{~mm}$ ) separator was used, soaked in an electrolyte consisting of $1 \mathrm{M} \mathrm{LiNO}_{3}$ (99.99\%, Sigma-Aldrich) in dimethyl sulfoxide (anhydrous, $>99.9 \%$, Sigma-Aldrich). All measurements were conducted in $1 \mathrm{~atm}$ dry oxygen atmosphere to avoid any negative effects of humidity and $\mathrm{CO}_{2}$. Galvanostatic discharge-charge was conducted on a Neware battery testing system. The specific capacity was calculated based on the mass of Super-P (SP) carbon black in the cathode electrode. In order to investigate the charge and discharge products and the corresponding structural and morphological changes, the cells were charged and discharged to the required voltages, and then opened in the glove box. The active materials were removed from the electrodes and washed with dimethyl sulfoxide before being used for ex-situ XRD, SEM, TEM, Raman and FTIR analyses.

\section{Computational methods}

The calculations were performed based on the density function theory approach $^{17}$ with the ABINIT software package (Louvain-la-Neuve, Belgium) ${ }^{18}$ The exchange-correlation energy function was represented by the local-density approximation, employing ultra-soft pseudopotential formalism. ${ }^{19}$ We used an energy cut-off of $350 \mathrm{eV}$. Different Monkhorst-Pack $k$-point sets were used. The maximum self-consistent field convergent tolerance was $<2 \times 10^{-6} \mathrm{eV}$ per atom. All calculations were performed in reciprocal space. For the surface energy calculation, the surface region was modeled as a finite number of two-dimensional infinite planes formed by cutting the crystal along a particular Miller index $(h k l)$ plane. In each plane, a two-dimensional cell represents every site in the plane. Following the approach of Tasker ${ }^{20}$, several of these cells in successive planes comprise the basic repeated unit that has the composition of the bulk crystal unit cell. The surface energy per unit area, $E^{h k l}$ surface, of a particular surface is calculated from the difference between the energy of the surface block, $E_{\text {surface block, }}$ and the energy of the same number of bulk ions, $E_{\text {bulk, }}$ per unit area, $A$ (cross-sectional), and thus

$$
E_{\text {surface }}^{h k l}=\left(E_{\text {surface }} \text { block }-E_{\text {bulk }}\right) / A \text {. }
$$

The variations in energy of the $\mathrm{Li}-\mathrm{O}_{2}$ reactions on the different facets of the polyhedral $\mathrm{Au} \mathrm{NCs}, E_{\mathrm{Li}-\mathrm{O} 2}^{h k l}$ reaction, were calculated from the difference between the $(h k l)$ surface energy, $E^{h k l}$ surface, the energy of $\mathrm{Li}_{2} \mathrm{O}_{2}$ monomer in vacuum, $E_{\mathrm{Li2O} 2}$, and the total energy of the interacting system of the $(h k l) \mathrm{Au}$ surface substrate and the supported $\left(\mathrm{Li}_{2} \mathrm{O}_{2}\right)_{\mathrm{n}}$ cluster, per unit area, $A$ (crosssectional), and thus

$$
E_{L i-O_{2} \text { reaction }}^{h k l}=\left[E^{h k l} \text { surface }+L i-O_{2}-\left(E^{h k l} \text { surface }-E_{L i_{2} O_{2}}\right)\right] / A
$$

For a slab model construction, enough layers were used, and the depths of the surface regions were chosen to be large enough to ensure full relaxation of the surface ions and convergence of the surface energy. In each case, the surface structures were fully relaxed until the total energy difference converged within $0.001 \mathrm{eV}$.

\section{RESULTS AND DISCUSSION}

\section{Morphology and crystal structure characterization}

The experimental methods involved in the preparation of $\mathrm{Au} \mathrm{NC}$ seeds and the subsequent addition of an appropriate quantity of the $\mathrm{Au}$ NC seed solution to the aqueous growth solutions. Supplementary Figure S1 shows the typical morphology of the Au NC seeds, which 
consist of a uniform octahedral shape and homogenous size distribution with an edge-to-edge width $\sim 50 \mathrm{~nm}$, and an apex-to-apex length of around $60 \mathrm{~nm}$. The TEM images (Supplementary Figure S2) further reveal their octahedral architecture and narrow size distribution. The morphologies of the polyhedral Au NCs, which were observed by FESEM, as shown in Figure 1, depend on the concentrations of the $\mathrm{Au}$ NC seeds and the surfactant (CTAB, CTAC), in addition to the reactants $\left(\mathrm{HAuCl}_{4}\right.$ and ascorbic acid). It can be seen that under the interaction between the Au NC seeds, surfactant and reactants, the $\mathrm{Au}$ NCs vary in terms of their polyhedral shapes: in $\sim 11 \mathrm{~mm} \mathrm{CTAB}$ and $0.134 \mathrm{~mm} \mathrm{Au}^{3+}$ ion solution, adjusted by $6.35 \mathrm{~mm}$ ascorbic acid, $\mathrm{Au}$ nanocubes with square outlines were formed (Figures $1 \mathrm{a}-\mathrm{c}_{6}$ ). From Figures $1 \mathrm{a}$ and $\mathrm{b}$, it is clearly observed that the as-prepared $\mathrm{Au}$ nanocubes are neatly arranged with uniform particle size $(\sim 65 \mathrm{~nm})$.
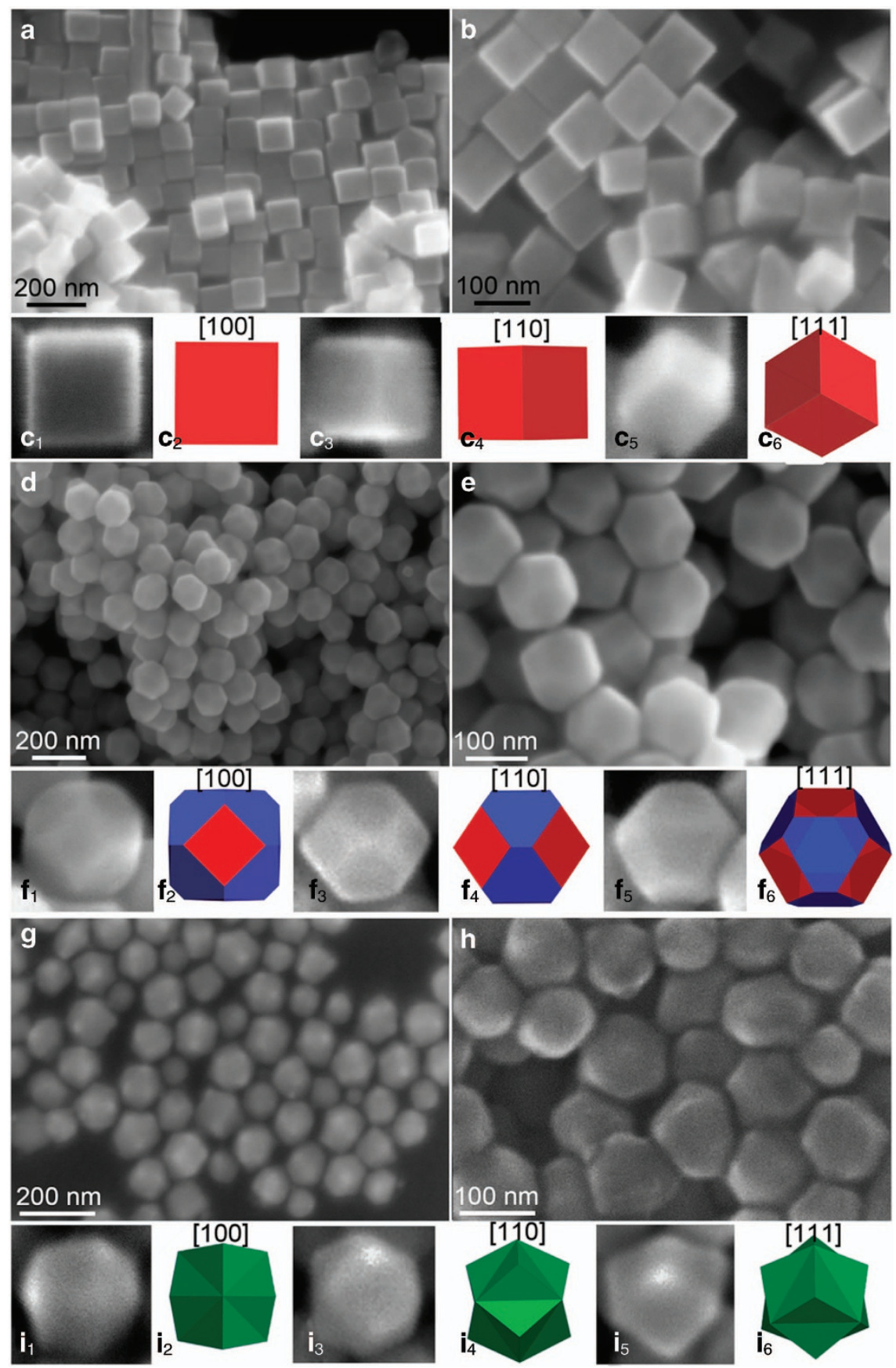

Figure 1 Low-magnification FESEM images of cubic Au NCs (a), T-OCT Au NCs (d) and TOH Au NCs (g). High-magnification FESEM images of cubic Au NCs (b), T-OCT Au NCs (e) and TOH Au NCs (h). $\left(\mathbf{c}_{1}-\mathbf{c}_{6}\right)$ : Individual cubic Au NCs in different orientations, with the corresponding geometrical models shown

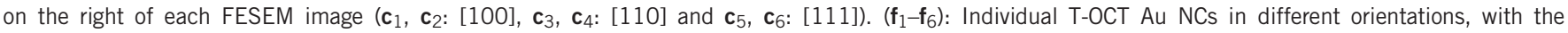
corresponding geometrical models shown on the right of each FESEM image $\left(\mathbf{f}_{1}, \mathbf{f}_{2}:[100], \mathbf{f}_{3}, \mathbf{f}_{4}:[110]\right.$ and $\mathbf{f}_{5}$, $\mathbf{f}_{6}$ : [111]). (i $\left.\mathbf{i}_{1}-\mathbf{i}_{6}\right)$ : Individual TOH Au NCs in different orientations, with the corresponding geometrical models shown on the right of each FESEM image $\left(\mathbf{i}_{1}, \mathbf{i}_{2}:[100], \mathbf{i}_{3}, \mathbf{i}_{4}:[110]\right.$ and $\left.\mathbf{i}_{5}, \mathbf{i}_{6}:[111]\right)$. 
Figures $1 c_{1}, c_{3}, c_{5}$ shows the outlines of individual cubic Au NCs viewed from different directions ([100], [110] and [111], respectively), which have been illustrated by the corresponding geometric models (Figures $1 c_{2}, c_{4}, c_{6}$, respectively). When reduce the concentrations of $\mathrm{Au}^{3+}$ ions and $\mathrm{Au} \mathrm{NC}$ seeds to one-third and increase the CTAB concentration, T-OCT Au NCs were obtained, as shown in Figures $1 \mathrm{~d}-\mathrm{f}_{6}$. The uniform T-OCT shape and particle size distribution are shown in Figures $1 \mathrm{~d}$ and e. The average crystal size was estimated to be $\sim 65 \mathrm{~nm}$. The individual T-OCT Au NCs, shown in Figures $1 \mathrm{f}_{1}, \mathrm{f}_{3}, \mathrm{f}_{5}$, present a different polyhedral shape with multiple facets along different orientations ([100], [110] and [111]), which are illustrated by the models in Figures $1 f_{2}, f_{4}, f_{6}$, respectively. On using CTAC to replace $\mathrm{CTAB}$ as the surfactant in a similar manner as for the synthesis of cubic Au NCs, Au NCs with a different morphology were achieved. The representative FESEM images shown in Figures $1 \mathrm{~g}-\mathrm{i}_{6}$ confirm that the majority of $\mathrm{NCs}(>95 \%)$ have a concave TOH architecture, which is an octahedron with each of its facets capped by a triangular pyramid. ${ }^{21}$ It is therefore a polyhedron enclosed by 24 high-index $\{h h l\} \quad(h>l>0)$ facets. The good agreement between the highmagnification FESEM images of the NCs in different orientations ([100], [110] and [111]) and the corresponding geometrical models of a trisoctahedron (Figures $1 \mathrm{i}_{1}-\mathrm{i}_{6}$ ) confirms the TOH geometry of the Au NCs. Obviously, all of the factors, including the Au NC seeds, the surfactant and the reactants, were found to be inter-dependent for preparing different polyhedral Au NCs. The monodispersion of the three different shaped Au NCs can be seen from the FESEM images at different magnifications in Supplementary Figure S3-S5.

Detailed crystal structure of the Au NCs was characterized by TEM analysis. Figure 2a shows a low-magnification TEM image of the cubic $\mathrm{Au}$ NCs. These nanocubes have almost perfectly sharp edges, corners and well-defined faces. Figures $2 b_{1}-b_{6}$ shows TEM images of individual cubic Au NCs viewed along the [100], [110] and [111] directions, respectively, as evidenced by the atomic models shown below each TEM image. The lattice-resolved HRTEM image collected from the Au NCs along the [100] direction clearly presents different crystal planes with a $90^{\circ}$ corner angle, indicating their single crystalline feature (Figure 2c). A further atomic resolved HAADF-STEM image of the (100) surface illustrates the square arrangement of atoms (Figure 2d). The characteristic square spot array of its corresponding fast-Fourier transform (FFT) pattern can be indexed along the [100] zone axis of $\mathrm{Au}$ (Figure 2e), which confirms that the Au nanocubes are enclosed by $\{100\}$ facets, as demonstrated by the simulated atomic arrangement of the $\mathrm{Au}(100)$ crystal plane (inset in Figure 2d). The regular atomic arrangement within the homogenous surface indicates its good crystallinity. The (020) and (011) crystal planes with lattice spacings of 0.20 and $0.288 \mathrm{~nm}$, respectively, and an interfacial angle of $45^{\circ}$ can be directly observed (Figure $2 \mathrm{~d}$ ). TEM images of T-OCT Au NCs are shown in Figures $2 \mathrm{f}-\mathrm{j}$. All the T-OCT Au NCs have welldefined facets, as shown in the low-magnification TEM image (Figure 2f). Figures $2 \mathrm{~g}_{1}-\mathrm{g}_{6}$ shows the outlines of T-OCT Au NCs lying along different orientations ( $g_{1}:[100], g_{3}:[110]$ and $\left.g_{5}:[111]\right)$. The corresponding atomic models of these T-OCT Au NCs (Figures $2 g_{2}, g_{4}, g_{6}$ ) clearly present their profiles, proving that Au NCs are enclosed by 14 well-defined facets. Figure $2 \mathrm{~h}$ shows a typical latticeresolved HRTEM image of a T-OCT Au NC that lies flat along the [111] zone axis, obtained by directing the electron beam perpendicular to the upper face of the NC. It exhibits a hexagonal shape that lies partly out of frame, with a $120^{\circ}$ corner angle, due to the special faceup direction. Figure $2 \mathrm{i}$ shows an atom-resolved HAADF-STEM image taken from Figure $2 \mathrm{~h}$, in which the $(2 \overline{2} 0),(20 \overline{2})$ and $(02 \overline{2})$ crystal planes with $0.144 \mathrm{~nm} d$-spacing can be directly observed. Together with its corresponding indexed FFT pattern (Figure 2j), it confirms that the exposed facets should be $\{111\}$. The atomic resolved HAADFSTEM image further demonstrates the regular hexagonal atom arrangement of the $\mathrm{Au}\{111\}$ surfaces, which is consistent with the simulated atomic array of $\mathrm{Au}\{111\}$ facets (inset in Figure 2i).

$\mathrm{TOH} \mathrm{Au}$ NCs bounded by high-index facets were formed at high yield. Figure 3a shows a typical low-magnification high-angle annular bright field TEM (HAABF-STEM) image of the monodisperse $\mathrm{TOH}$ $\mathrm{Au}$ NCs. The concave TOH outlines of individual Au NCs can be observed in the corresponding HAADF-STEM and secondary electron STEM images (Figures $3 \mathrm{~b}$ and $\mathrm{c}$ ). The oriented TOH Au NCs in the high-magnification HAADF-STEM images (where Figures $3 d_{1}, d_{3}, d_{5}$ and $d_{7}$ ) corresponds to the [100], [110], [111] and [441] orientations, respectively) are consistent with the geometrical models of a concave TOH (Figures $3 \mathrm{~d}_{2}, \mathrm{~d}_{4}, \mathrm{~d}_{6}$ and $\mathrm{d}_{8}$ ), respectively) when viewed from different directions. The corresponding HAABF-STEM and secondary electron scanning TEM images are shown in Supplementary Figure S6 in the Supplementary Information. The white solid lines marked in Figures $3 d_{1}, d_{3}, d_{5}$ were used to accentuate the edges and angles that form the outline of the triangular pyramids sitting on the octahedral facets. It can be seen from Figure $3 \mathrm{~d}_{4}$, that when a $\mathrm{TOH}$ is viewed along the [110] direction, four edge-on facets can be projected, as indicated by the arrows. ${ }^{22}$ The Miller indices of the edge-on facets of a $\mathrm{TOH}$ can be determined through an analysis of the projection angles. $^{23}$ The values of the three different angles, $\alpha, \beta$ and $\gamma$, corresponding to different Miller indices of a perfect $\mathrm{TOH}$ crystal, are given in Supplementary Table S1. ${ }^{16,17}$ The angles of the projection have been measured and are marked in the Figure $3 \mathrm{~d}_{3}$. By comparing the measured angles with the calculated values in Supplementary Table S1, we found that the TOH Au NCs were bounded by $\{441\}$ facets. Figure $3 \mathrm{e}$ shows an atomic resolved HAADF-STEM image of a TOH $\mathrm{Au}$ NC taken along the [110] direction, as confirmed by its corresponding FFT pattern (top-left corner inset of Figure 3e), in which the (002) and (111) crystal planes with 0.2 and $0.235 \mathrm{~nm} d$ spacings, respectively, can be directly observed. The atom arrangement of $\{110\}$ facets was also simulated by the model shown in the middle inset of Figure 3e. In this model, the projected $\{110\}\{111\},\{221\}$, $\{331\}$ and $\{441\}$ crystal planes along the [110] direction can be observed directly. By comparison, only the projected $\{441\}$ crystal plane can match the atomic arrangement on the edge of the atomic resolved HAADF-STEM image, which can confirm that the edge-on facet in Figure $3 e$ is the (441) surface. Furthermore, it can be seen that the $\{441\}$ crystal plane can be considered of as a combination of (110) terraces and a (001) step. When the $\{110\}$ surface is rotated $10^{\circ}$ along the [001] axis, the $\{441\}$ facet is exposed, as shown in Supplementary Figure $\mathrm{S}_{6} \mathrm{~d}_{2}$. With smaller $d$-spacings, the $(2 \overline{2} 0)$ and $(\overline{1} 04)$ crystal planes $(0.144$ and $0.099 \mathrm{~nm}$, respectively) were observed in the atomic resolved HAADF-STEM image. Through the corresponding FFT pattern (Supplementary Figure $\mathrm{S} \mathrm{d}_{3}$ ), it can be confirmed that the exposed facets should be $\{441\}$, according to the indexed crystal plane spots.

Owing to the different crystal planes exposed by the three polyhedral Au NCs, different colors are presented when they are dispersed in an aqueous solution, as shown in Supplementary Figure S7. More TEM images in the Supplementary Information (Supplementary Figure S8-S10) show the uniform crystal size distribution and more morphological, surface and crystal structural information of the three different types of polyhedral Au NCs.

The Miller indices of high-index facets could also be identified from the atomic arrangement in the edge-on facets. High-index planes can be exhibited as ordered terrace-step structures, $m\left(h_{\mathrm{t}} k_{\mathrm{t}} l_{\mathrm{t}}\right) \times\left(h_{\mathrm{s}} k_{\mathrm{s}} l_{\mathrm{s}}\right)$, 


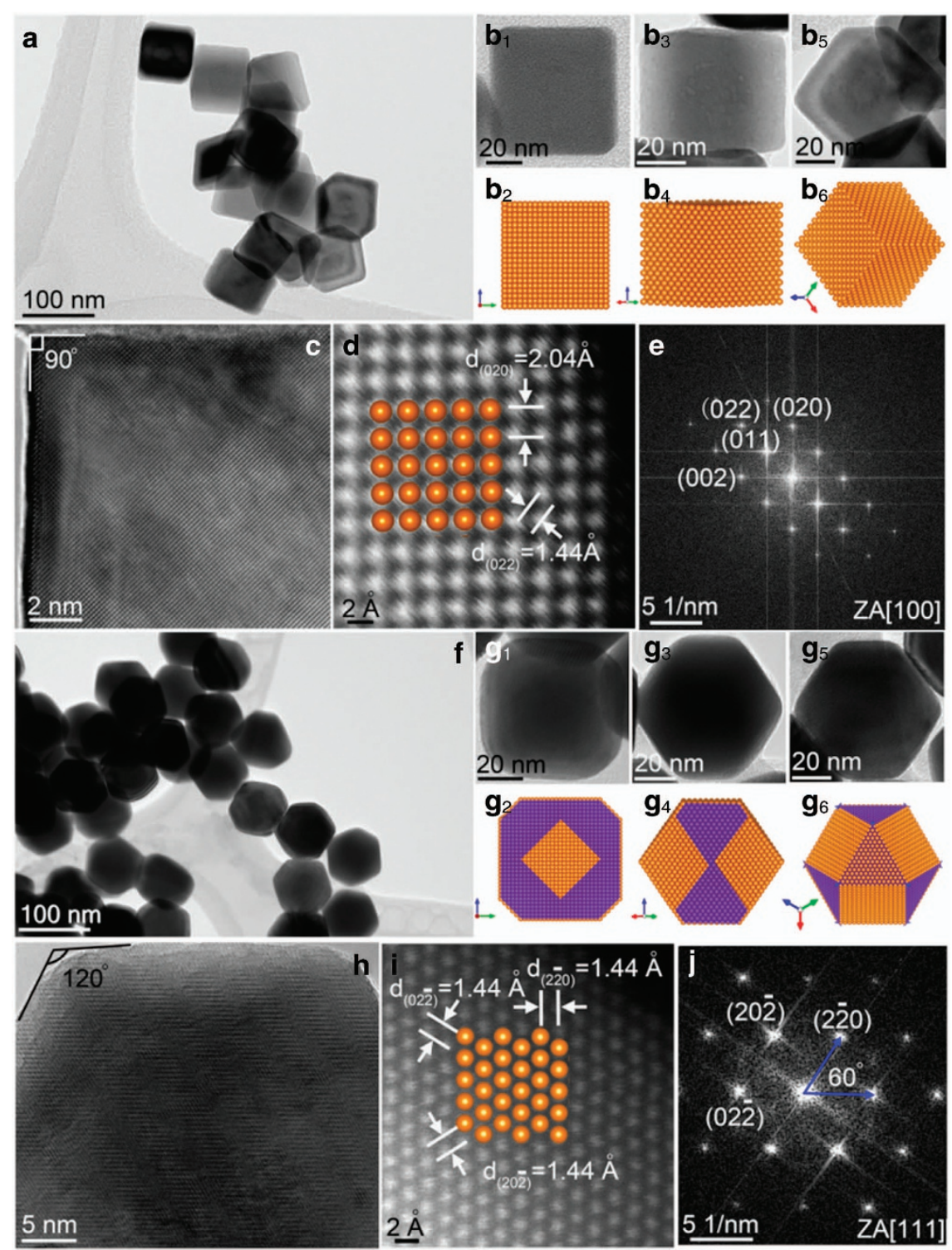

Figure 2 (a) Low-magnification TEM image of cubic Au NCs. $\left(\mathbf{b}_{1}-\mathbf{b}_{6}\right)$ High-magnification TEM images of individual cubic Au NCs viewed from different

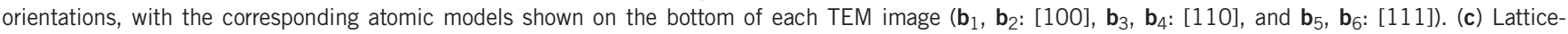
resolved HRTEM image of cubic Au NCs collected along the [100] direction. (d) Atomic resolved HAADF-STEM image of cubic Au NC \{100\} facets, with (e) its corresponding FFT pattern along the [100] zone axis. (f) Low-magnification TEM image of T-OCT Au NCs. ( $\mathbf{g}_{1}-\mathbf{g}_{6}$ ) High-magnification TEM images of individual T-OCT Au NCs viewed from different orientations, with the corresponding atomic models shown on the bottom of each TEM image ( $\mathbf{g}_{1}, \mathbf{g}_{2}$ : [100], $\mathbf{g}_{3}, \mathbf{g}_{4}$ : [110] and $\mathbf{g}_{5}, \mathbf{g}_{6}$ : [111]). (h) Lattice-resolved HRTEM image of T-OCT Au NCs taken along the [111] direction. (i) Atomic resolved HAADF-STEM image of T-OCT Au NC $\{111\}$ facets, with (j) its corresponding FFT pattern along the [111] zone axis. Insets of (d) and (i) are the simulated atom arrangements of the $\{100\}$ and $\{111\}$ facets.

which means $m$ atomic widths of $\left(h_{\mathrm{t}} k_{\mathrm{t}} l_{\mathrm{t}}\right)$ terraces with a monatomic $\left(h_{\mathrm{s}} k_{s} l_{\mathrm{s}}\right)$ step. ${ }^{22}$ Accordingly, the $\{111\},\{221\},\{331\}$ and $\{441\}$ planes consist of 1,2, 3 and 4 atomic widths of (110) terraces with one (001) step, respectively, as shown in Supplementary Figure S11a. The atomic models of $\{100\},\{111\}$ and $\{441\}$ planes are shown in Supplementary Figures $\mathrm{S} 1 \mathrm{~b}, \mathrm{c}_{1}$ and $\mathrm{d}_{1}$, respectively. Supplementary Figures $S 11 \mathrm{c}_{2}$ and $\mathrm{d}_{2}$ illustrates the $\{111\}$ and $\{441\}$ crystal planes projected from the $[00 \overline{1}]$ zone axis, from which it can be clearly seen that the atomic arrangement of the $\{441\}$ facets is periodically composed of four atomic widths of (110) terraces, followed by one atomic width of a (001) step, which is, a multiple height-stepped structure. These steps have been directly captured in the atomic resolved HAADF-STEM image (top-left corner inset of Figure $3 \mathrm{e}$ ). The atomic model of the
$\{441\}$ facet has a high density of stepped surface atoms compared with the $\{111\}$ facet.

\section{Growth mechanisms}

The formation of NCs with geometrical shapes is controlled by the reaction microenvironment. ${ }^{24}$ Selective 'face-blocking' and the reduction rate of the metal ions governs the growth kinetics. The former involves the selective adsorption of species in the growth solution onto specific crystallographic facets, hindering the access to these facets of the metal atoms that are being deposited, and on contrary, promoting the relative growth rates of other facets. The latter determines the speed at which the metal atoms are deposited. 

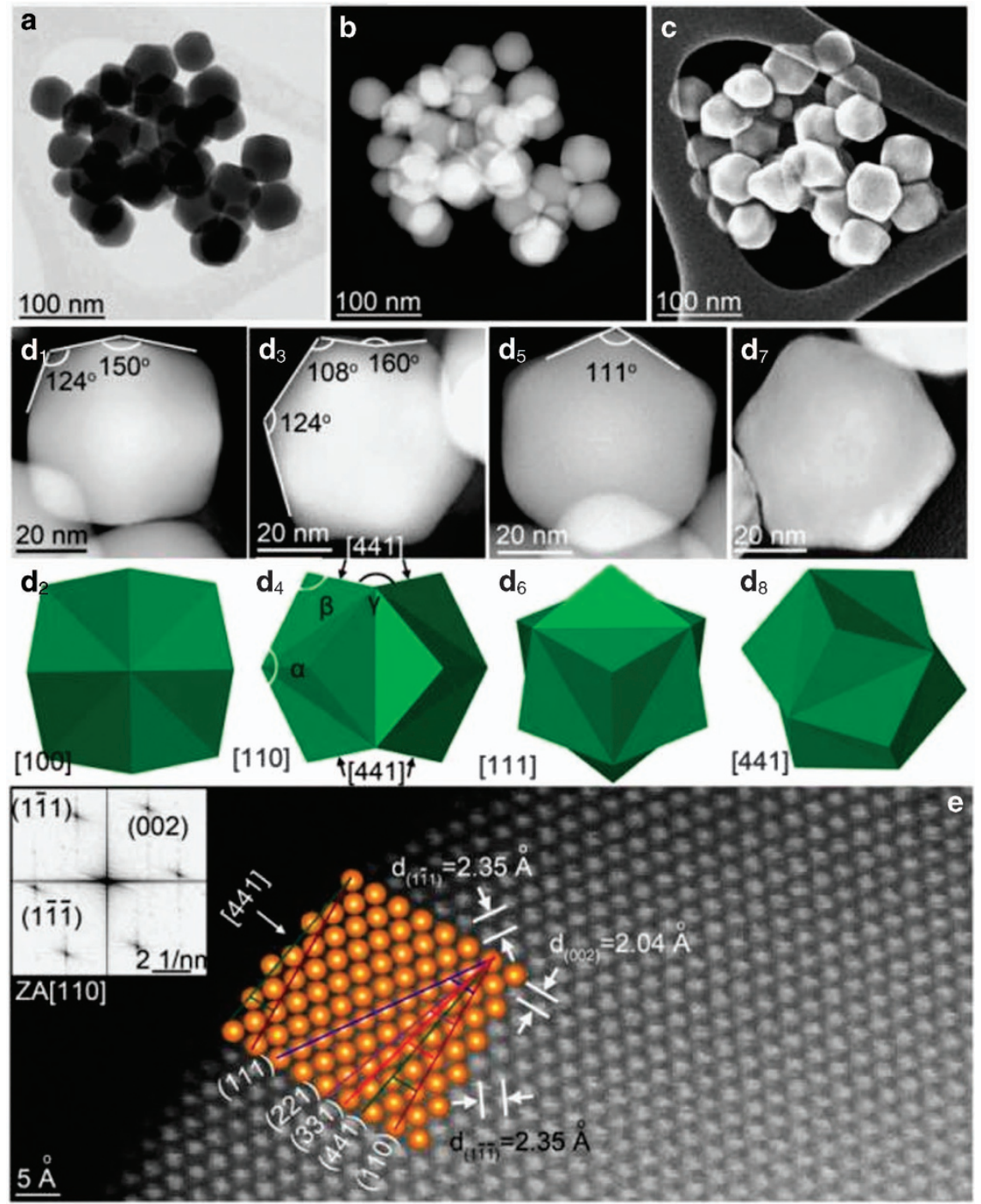

Figure 3 (a) Low-magnification high-angle annular bright field scanning TEM (HAABF-STEM) image of TOH Au NCs. (b and c) are HAADF-STEM and secondary electron scanning TEM images, respectively, corresponding to (a). ( $\mathbf{d}_{1}, \mathbf{d}_{3}, \mathbf{d}_{5}, \mathbf{d}_{7}$ ) High-magnification HAADF-STEM images of individual TOH Au NCs viewed from different orientations. $\left(\mathbf{d}_{2}, \mathbf{d}_{4}, \mathbf{d}_{6}\right.$ and $\mathbf{d}_{8}$ ) are the corresponding geometrical models for $\left(\mathbf{d}_{1}, \mathbf{d}_{3}, \mathbf{d}_{5}\right.$ and $\mathbf{d}_{7}$ ), respectively. $\left(\mathbf{d}_{1}, \mathbf{d}_{2}\right.$ : [100], $\mathbf{d}_{3}, \mathbf{d}_{4}$ : [110], $\mathbf{d}_{5}, \mathbf{d}_{6}$ : [111] and $\mathbf{d}_{7}, \mathbf{d}_{8}$ : [441]). (e) Atomic resolved HAADF-STEM image of TOH Au NCs taken along the [110] direction, showing the (441) surface, (110) terraces and (001) step. Top-left corner inset of (e) is the corresponding indexed FFT pattern along the [110] zone axis. The middle inset of (e) is the simulated atomic arrangement of $\{110\}$ facets, showing the projected $\{110\}\{111\},\{221\},\{331\}$ and $\{441\}$ crystal planes along the [110] direction.

Our reaction system contained three species that could act as the selective 'face-blockers', the reducing agent (ascorbic acid), the gold precursor $\left(\mathrm{HAuCl}_{4}\right)$ and the capping agent (surfactant: $\mathrm{CTAB}$ or CTAC). The large cationic surfactant molecule $\mathrm{CTA}^{+}$would play the pivotal role as a face-blocking agent in the formation of polyhedral $\mathrm{Au}$ NCs. It is believed that the shape of the fine Au seeds produced in the presence of CTAB is faceted with the most stable $\{111\}$ facets, which are solvent-accessible. ${ }^{25} \mathrm{CTAB}$ molecules appear to bind more strongly to the $\{100\}$ than the $\{111\}$ facets. $^{26}$ Thus, lower CTAB concentration conditions favor the faster deposition of $\mathrm{Au}$ atoms onto the $\{111\}$ facets, leading to their disappearance, and the formation of $\{100\}$ facets, thereby producing cubic shapes. Under slightly higher CTAB concentrations, one could expect truncated polyhedra with both $\{100\}$ and $\{111\}$ faces. ${ }^{27}$ When CTAB was replaced by CTAC at the same concentration in the synthesis, TOH Au NCs bounded by $\{441\}$ facets dominated in the final product. The difference between CTAB and CTAC is in the anions $\left(\mathrm{Br}^{-}\right.$and $\left.\mathrm{Cl}^{-}\right)$. The competition between $\mathrm{Cl}^{-}$ and $\mathrm{CTA}^{+}$for adsorption on the gold $\mathrm{NC}$ surface could be the cause of the TOH morphology. As $\mathrm{Cl}^{-}$has a lower affinity to gold than $\mathrm{Br}^{-}, 28$ $\mathrm{Cl}^{-}$would preferentially adsorb on the gold surface to create a negatively charged layer, where $\mathrm{CTA}^{+}$could subsequently bind through electrostatic interactions. ${ }^{29}$ Pre-adsorbed $\mathrm{Cl}^{-}$cannot screen the selective adsorption of $\mathrm{CTA}^{+}$on the high-index facets because of its lower affinity compared with $\mathrm{Br}^{-}$. Binding of the large $[\mathrm{NMe} 3]^{+}$ head group of $\mathrm{CTA}^{+}$(diameter $=0.814 \mathrm{~nm}$ ) and its associated long alkyl tail can be more easily accommodated on less closely packed high-index planes than on low-index planes. ${ }^{26,30}$ This is because the $\mathrm{Au}$ atomic spacing of high-index planes is comparable to the size of the $\mathrm{CTA}^{+}$head group. ${ }^{31}$ Therefore, when gold atoms reduced from the reaction mixture are deposited on the surface of a seed, $\mathrm{CTA}^{+}$ 
would selectively bind to the high-index facets, thereby preventing the latter from growing as fast as the others. With the deposition of more Au atoms, more high-index facets are created and protected by $\mathrm{CTA}^{+}$, while the low-index facets slowly disappear, facilitating the formation of TOH NCs. ${ }^{32}$ Besides the capping agent, an appropriate reduction rate is necessary to sustain the polyhedral shape. The concentration of the reducing agent (ascorbic acid) in the growth solution provides the means to alter the rate of generation of the $\mathrm{Au}$ atoms. ${ }^{32}$

\section{Electrochemical performance of $\mathrm{Au} \mathrm{NCs} @ S P$ in $\mathrm{Li}-\mathrm{O}_{2}$ cells}

The electrocatalytic activities of three different polyhedral Au NCs catalysts loaded on carbon black (Super-P, SP) were examined in $\mathrm{Li}-\mathrm{O}_{2}$ cells and compared with bare SP. The loaded Au NCs catalysts were around $40 \mathrm{wt} . \%$ as revealed by thermogravimetric analysis (Supplementary Figure S12). The galvanostatic charge-discharge measurements were carried out to evaluate the electrochemical performances in the voltage range of 2.0-4.3 V for Au NCs@SP and 2.0-4.6 V for bare SP at room temperature. Typical charge-discharge voltage profiles are shown in Figure 4a. The initial discharge capacities of the polyhedral Au NCs@SP electrodes are significantly higher than that of the bare SP electrode $\left(8980 \mathrm{mAh} \mathrm{g}^{-1}\right)$. Furthermore, the TOH@SP electrode achieved the highest discharge capacity, 20298 mAhg-1, followed by the T-OCT Au NCs@SP and cubic Au NCs@SP electrodes (16245 and $14115 \mathrm{mAhg}^{-1}$, respectively). The discharge plateau of the Au NCs@SP electrodes is slightly higher than that of the bare SP electrode $(2.68 \mathrm{~V})$ and shows an increasing tendency in the order of cubic Au NCs@SP $<$ T-OCT Au NCs@SP $<\mathrm{TOH}$ Au NCs@SP, indicating that the polyhedral Au NCs have catalytic activity toward the ORR. In the charge process, significant differences in the charge plateau were observed between the polyhedral Au NCs@SP electrodes and the bare SP electrode $(4.38 \mathrm{~V}$ for the bare SP electrode, $<3.77 \mathrm{~V}$ for the polyhedral Au NCs@SP electrodes). The polyhedral Au NCs@SP electrodes show much lower charge plateaus than the bare SP electrode, illustrating the excellent catalytic activity toward the OER of the Au NC catalysts. The overpotential between the charge and discharge processes has been significant decreased by adding the polyhedral Au NC catalysts. The TOH Au NCs@SP electrode presents the lowest charge potential (3.68 V), followed by the T-OCT Au NCs@SP and cubic Au NCs@SP electrodes in order $(3.72$ and $3.76 \mathrm{~V}$, respectively), suggesting that the different crystal planes of Au NCs have different catalytic activity toward the OER. When cycling the polyhedral Au NCs@SP electrodes at high current density $\left(400 \mathrm{~mA} \mathrm{~g}^{-1}\right)$, a similar tendency can be observed, as shown in Supplementary Figure S13. The TOH Au NCs@SP electrode also achieved the highest capacity, $14593 \mathrm{mAhg}^{-1}$, followed by the T-OCT Au NCs@SP and cubic Au NCs@SP electrodes (13665 and $12991 \mathrm{mAhg}^{-1}$, respectively). Moreover, the TOH Au NCs@SP electrode demonstrated the lowest overpotential, $0.95 \mathrm{~V}(2.82 \mathrm{~V}$ for discharge potential, $3.77 \mathrm{~V}$ for the charge potential), as shown by the differential profiles of the chargedischarge curves (Supplementary Figure S13b). Moreover, the sharp reduction peaks during the cathodic process indicate the good catalytic activity of polyhedral Au NCs@SP electrodes toward the ORR, while the strong oxidation peaks in the anodic process indicate the good catalytic activity toward the OER. Furthermore, from the long cycle performance of full charge and discharge (Supplementary Figure S14), it can be seen that the TOH Au NCs@SP electrodes still maintain the high discharge capacity.

The electrochemical performance of polyhedral Au NCs@SP electrodes was further examined by restricting the capacity during cycling at various current densities. Supplementary Figure S15 shows a

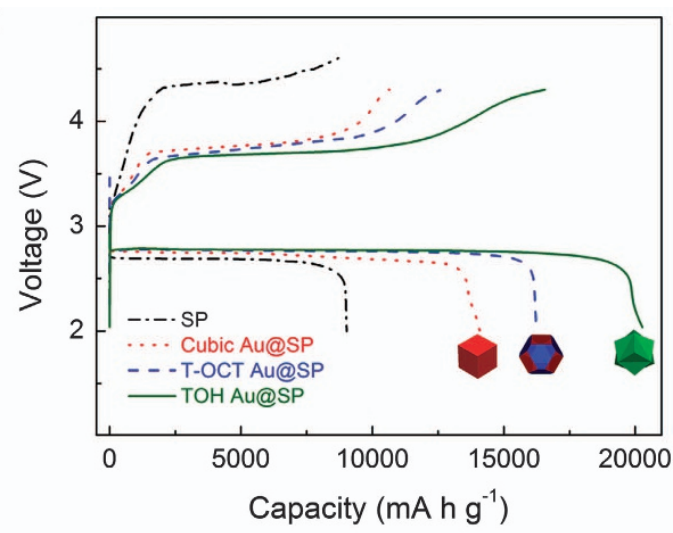

b

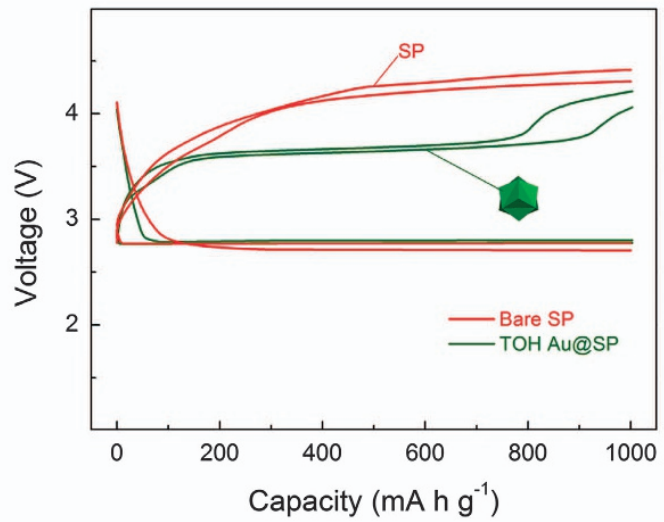

C

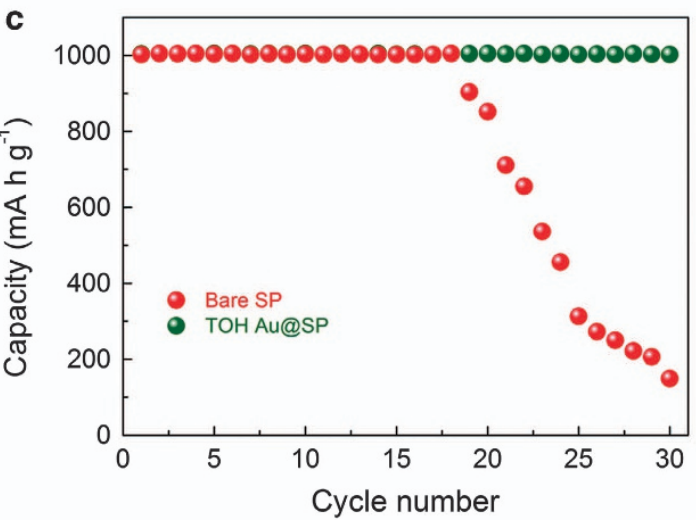

Figure 4 (a) Charge-discharge curves of the cubic Au NCs@SP (red solid line), T-OCT Au NCs@SP (blue solid line), TOH Au NCs@SP (green solid line) and bare SP electrodes (black solid line) at $100 \mathrm{mAg}^{-1}$ in the first cycle. (b) The first and tenth cycle profiles of SP and TOH Au NCs@SP electrodes with the capacity restricted to $1000 \mathrm{mAhg}^{-1}$ at $200 \mathrm{mAg}^{-1}$ current density. (c) Cycling performance of SP and TOH Au NCs@SP electrodes with the capacity restricted to $1000 \mathrm{mAhg}^{-1}$ at $500 \mathrm{mAg}^{-1}$ current density.

the voltage profiles of polyhedral Au NCs@SP electrodes cycled at $200 \mathrm{~mA} \mathrm{~g}^{-1}$ with the capacities restricted to $1000 \mathrm{~mA} \mathrm{~h} \mathrm{~g}^{-1}$. It can be seen that all the polyhedral Au NCs@SP electrodes display a discharge plateau at about 2.8 V. Furthermore, the TOH Au NCs@SP electrode presents the lowest charge plateau, at $3.63 \mathrm{~V}$, as revealed by the differential profiles (Supplementary Figure S16a). By comparison with the bare SP electrode, the TOH Au@SP electrode largely decreases the overpotential, as shown in Figure $4 \mathrm{~b}$. The low charge potentials of these polyhedral Au NCs@SP electrodes can be maintained at the 

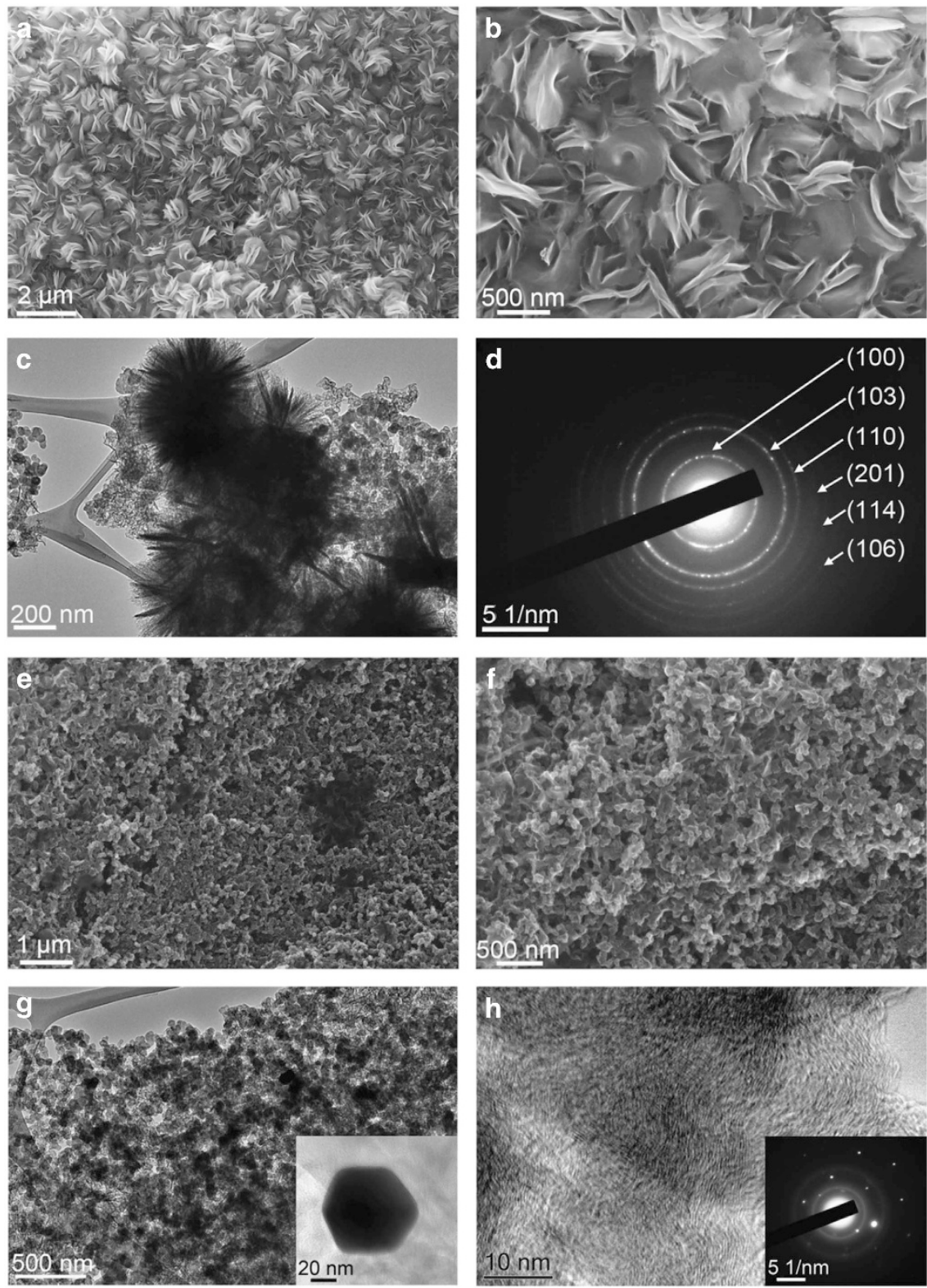

Figure 5 (a and b) Ex-situ SEM images of fully discharged TOH Au NCs@SP electrode. (c) Ex-situ TEM image of the fully discharged TOH Au NCs@SP electrode. (d) is the corresponding selected area electron diffraction pattern. (e and f) Ex-situ SEM images of fully charged TOH Au NCs@SP electrode. (g) TEM image of general morphology of charged TOH Au NCs@SP electrode. Inset of (g) shows HRTEM image of an Au NC. (h) The HRTEM image of SP. Inset of $(\mathbf{h})$ is the SAED pattern, corresponding to inset of $(\mathbf{g})$, demonstrating the preservation of the crystalline features of Au NCs after cycling.

tenth cycle, and the TOH Au NCs@SP always yields the lowest values compared with the T-OCT Au NCs@SP and cubic Au NCs@SP electrodes (Supplementary Figure S15). When the current density was increased to $500 \mathrm{mAg}^{-1}$, the same trend was also observed (Supplementary Figure S16b). The TOH Au@SP electrode can sustain cycling for more than 30 cycles, while the bare SP electrode failed after 18 cycles, as shown in Figure 4c. Even when the current density was increased to $1000 \mathrm{mAg}^{-1}$, the TOH Au NCs@SP electrode still presented much a lower charge plateau than the T-OCT Au NCs@SP and cubic Au NCs@SP electrodes (Supplementary Figure S16c). As confirmed by the differential profiles of the charge curves (Supplementary Figure S16d). These observations indicate that polyhedral $\mathrm{Au}$ NCs with different exposed crystal planes have different catalytic activity toward OER. In particular, the TOH Au NCs achieved the highest catalytic activity toward the OER.

To identify the charge and discharge products, we conducted ex-situ $\mathrm{XRD}, \mathrm{SEM}$ and TEM measurements. As confirmed by the ex-situ XRD pattern (Supplementary Figure S17) of the TOH Au NCs@SP electrode, the main discharge products are $\mathrm{Li}_{2} \mathrm{O}_{2}$ (JCPDS Card No. 09-0355), with hexagonal symmetry (space group: $P \overline{6}$ ). After being fully charged, the $\mathrm{Li}_{2} \mathrm{O}_{2}$ was totally decomposed, which was also confirmed from the ex-situ XRD patterns. The morphologies of the TOH Au NCs@SP electrode in the fully discharged and charged states were analysed by ex-situ FESEM and TEM (as shown in Figure 5). From Figure $5 \mathrm{a}$, it can be seen that after being full discharged, the TOH Au NCs@SP electrode was covered with the discharge product $\mathrm{Li}_{2} \mathrm{O}_{2}$. For comparison, a FESEM image of the pristine $\mathrm{TOH} \mathrm{Au}$ 
NCs@SP electrode is presented in Supplementary Figure S18. From the high magnification FESEM image (Figure 5b), it can be identified that the $\mathrm{Li}_{2} \mathrm{O}_{2}$ has toroid-like morphology with $\sim 500 \mathrm{~nm}$ particle size, which is similar to previously reported $\mathrm{Li}_{2} \mathrm{O}_{2}$ morphology. ${ }^{9,33}$ The exsitu TEM image shows that the $\mathrm{Li}_{2} \mathrm{O}_{2}$ features wrinkles (Figure $5 \mathrm{c}$ ), which are composed of the $\mathrm{Li}_{2} \mathrm{O}_{2} \mathrm{NCs}$, and its corresponding SAED pattern can be well indexed as crystalline hexagonal $\mathrm{Li}_{2} \mathrm{O}_{2}$ (Figure $5 \mathrm{~d}$ ). When we fully charged the cell, all the discharge products completely disappeared (Figures 5e and f). The corresponding ex-situ TEM images of the charged electrode are shown in Figures $5 \mathrm{~g}$ and $\mathrm{h}$, along with TEM images of the amorphous carbon (SP) and well crystallized Au NCs after the cycling. The inset of Figure $5 \mathrm{~g}$ shows the HRTEM image of the Au NC and SP; while the inset of Figure $5 \mathrm{~h}$ is the SAED pattern, demonstrating the preservation of the crystalline features of the $\mathrm{Au}$ NCs after cycling. These results suggest the high reversibility of the TOH Au NCs@SP electrode. Similarly, the cubic Au NCs@SP and T-OCT Au NCs@SP electrodes also yielded the toroid-shaped $\mathrm{Li}_{2} \mathrm{O}_{2}$ discharge products, which could be completely oxidized and removed from the surface after the charging process, as shown in Supplementary Figures S19 and S20, respectively.

To confirm the main discharge products after long cycling, the fully discharged TOH Au NCs@SP electrodes after 20 cycles were investigated by ex-situ XRD, Raman and FTIR measurements. From the ex-situ XRD patterns (Supplementary Figure S21), it can be seen that the peaks at around $23^{\circ}, 33^{\circ}, 35^{\circ}, 40^{\circ}$ and $58^{\circ}$ (as marked by the red solid circle) indicate the formation of $\mathrm{Li}_{2} \mathrm{O}_{2}$, while the peaks at around $21^{\circ}, 30^{\circ}, 32^{\circ}, 37^{\circ}$ and $53^{\circ}$ (as marked by the black star) can be assigned to the by-product $\mathrm{LiOH} \cdot \mathrm{H}_{2} \mathrm{O}$. Raman and FTIR measurements further confirmed the discharge products (as shown in Supplementary Figures S22 and S23, respectively). In the Raman spectrum, two main Raman shifts at 1320 and $1600 \mathrm{~cm}^{-1}$ correspond to the D-bond and G-bond of carbon. The Raman shifts at around 260, 787 and $2630 \mathrm{~cm}^{-1}$ prove the existence of $\mathrm{Li}_{2} \mathrm{O}_{2}$. The broad peak at $2919 \mathrm{~cm}^{-1}$ could be assigned to $\mathrm{LiOH} \cdot \mathrm{H}_{2} \mathrm{O}$. From the FTIR spectrum, the formation of $\mathrm{Li}_{2} \mathrm{O}_{2}$ can be further identified by the peak at around $470 \mathrm{~cm}^{-1}$. The other peaks in the FTIR spectrum demonstrate the by-product $\mathrm{LiOH} \cdot \mathrm{H}_{2} \mathrm{O}$, which could originate from trace moisture in the electrolyte.

\section{Mechanism of $\mathrm{Li}_{2} \mathrm{O}_{2}$ formation}

A possible mechanism for the Au NCs ORR/OER activity is shown in Scheme 1 . As previously determined, ${ }^{33,34}$ the $\mathrm{O}_{2}$ is first bound to the cathode surface via the oxygen vacancies, especially on the carbon defect sites and $\mathrm{Au} \mathrm{NC}$ catalyst, followed by reduction to $\mathrm{O}_{2}{ }^{-}$. The stabilized superoxide ion could be combined via the dismutase reaction to form $\mathrm{Li}_{2} \mathrm{O}_{2} \cdot{ }^{33}$ This mechanism is supported by the presence of large $(\sim 500 \mathrm{~nm})$ uniform toroid-shaped $\mathrm{Li}_{2} \mathrm{O}_{2}$ particles formed on discharge. Additionally, as revealed by the TEM images, the large toroid-shaped $\mathrm{Li}_{2} \mathrm{O}_{2}$ particles are composed of aggregates of $\mathrm{Li}_{2} \mathrm{O}_{2}$ NCs. This provides evidence for proposing that the solvated $\mathrm{LiO}_{2}$ is initially formed when the ORR catalysis reaches a local high saturation concentration. The $\mathrm{Li}_{2} \mathrm{O}_{2}$ nucleates to create NCs because of its low solubility and is gradually deposited to form the observed 'tortellini' aggregate morphology. ${ }^{33}$

For the OER process on charge, it was proposed that the peroxide is decomposed into $\mathrm{Li}^{+}$and $\mathrm{O}_{2}{ }^{2-}$ on the vacant catalyst sites first, and then stepwise oxidized to $\mathrm{O}_{2}^{-}$and $\mathrm{O}_{2}$, which can be proved by the exsitu SEM and TEM images. The catalyst stability was demonstrated after ten cycles, as evidenced by Supplementary Figure S24, where the toroids are obtained on the discharge process and completely disappear after the charge process.

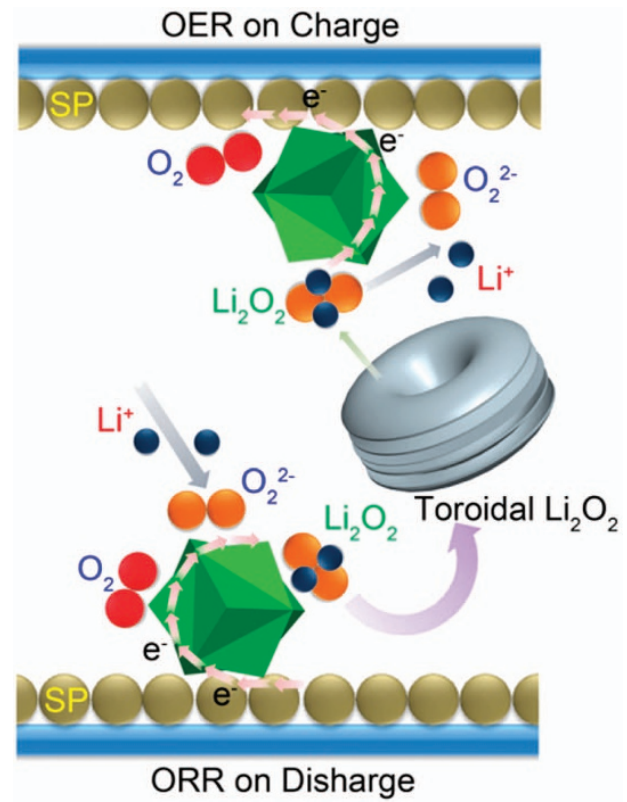

Scheme 1 Schematic diagram of the proposed Au NC catalyst mechanism in the $\mathrm{Li}-\mathrm{O}_{2}$ cell.

The electrochemical performance of the polyhedral Au NCs@SP electrodes clearly demonstrates that the Au NCs with different exposed crystal planes have different effects on the catalytic activity toward the ORR and OER in the $\mathrm{Li}-\mathrm{O}_{2}$ battery. In principle, the NCs' properties are determined by the exposed crystal facets. ${ }^{35,36} \mathrm{NCs}$ that have particular exposed crystal planes with high-index facets could achieve improved chemical or physical performances, because high-index facets have high densities of atom steps, edges, kinks and dangling bonds, which usually have high chemical activity. ${ }^{37}$ Therefore, the surface properties are expected to play a key role in understanding the electrochemical behavior in $\mathrm{Li}-\mathrm{O}_{2}$ systems. Obviously, the cubic $\mathrm{Au}$ NCs, T-OCT Au NCs and TOH Au NCs are enclosed by different facets $(\{100\},\{111\}$ and $\{441\}$ crystal planes) with different arrangements of atoms, which may be responsible for the different ORR and OER performances.

To investigate the various catalytic activities of the polyhedral Au NCs, we conducted density function theory calculations on the different Au crystal planes and their interaction with the $\mathrm{Li}$ and $\mathrm{O}$ atoms. The relaxed surface energies and interaction energies with $\mathrm{Li}$ and $\mathrm{O}$ atoms of different Au crystal planes are listed in Table 1. The $\{100\}$ crystal plane has the lowest surface energy of $1.32 \mathrm{~J} \mathrm{~m}^{-2}$, suggesting that it is the most stable facet. The $\{111\}$ crystal planes show relatively higher surface energy $\left(1.60 \mathrm{~J} \mathrm{~m}^{-2}\right)$. The most active crystal planes for $\mathrm{Au}$ are the $\{441\}$ facets, with the highest surface energy of $2.55 \mathrm{~J} \mathrm{~m}^{-2}$, which is almost twice that of the $\{100\}$ crystal planes. The atomic arrangement of the $\mathrm{Au}\{441\}$ surface is composed of a periodic multiple height-stepped structure (as shown in Supplementary Figure S11), ${ }^{38}$ which could present high reactivity, ${ }^{39}$ resulting in the high surface energy. As for the interaction between different crystal planes of $\mathrm{Au}$ and the $\mathrm{Li}$ and $\mathrm{O}$ atoms, it can be observed that as the surface energy of the Au crystal planes increases, the interaction energy between the $\mathrm{Au}$ and the $\mathrm{Li}$ and $\mathrm{O}$ atoms decreases. The $\{441\}$ crystal planes yield the lowest interaction energy $\left(1.64 \mathrm{~J} \mathrm{~m}^{-2}\right)$, while $\{100\}$ crystal planes show the highest value $(4.00$ $\mathrm{J} \mathrm{m}^{-2}$ ). Apparently, the $\{441\}$ crystal planes show the highest activity because of their high surface energy, which can provide more reactive 
Table 1 The surface energies of the $\{100\},\{111\}$ and $\{441\}$ crystal planes, and their reaction energy with $\mathrm{Li}$ and $\mathrm{O}$ atoms

\begin{tabular}{lcc}
\hline Facets & Surface energy $\left(\mathrm{J} \mathrm{m}^{-2}\right)$ & Reaction energy $\left(\mathrm{J} \mathrm{m}^{-2}\right)$ \\
\hline$\{100\}$ & 1.32 & 4.00 \\
$\{111\}$ & 1.60 & 3.81 \\
$\{441\}$ & 2.55 & 1.64 \\
\hline
\end{tabular}

sites to facilitate the interaction with $\mathrm{Li}$ and $\mathrm{O}$ atoms, and therefore, they consume the lowest energy to accomplish the $\mathrm{Li}$ and $\mathrm{O}$ reactions. Recently, it was reported that the oxygen adsorption energy on the surface can significantly influence the $\mathrm{Li}^{+}$oxygen reduction activity. ${ }^{40}$ The oxygen adsorption energy on the surface of the $\{441\}$ crystal planes is lower than for the $\{100\}$ and $\{111\}$ crystal planes, which makes $\mathrm{TOH} \mathrm{Au}$ NCs more active toward the OER, leading to an enhanced electrochemical performance. Similarly, cubic Au NCs and a

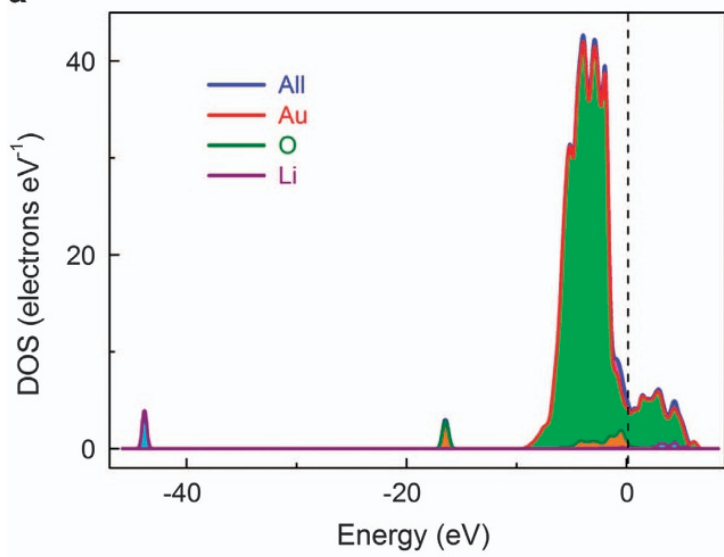

C
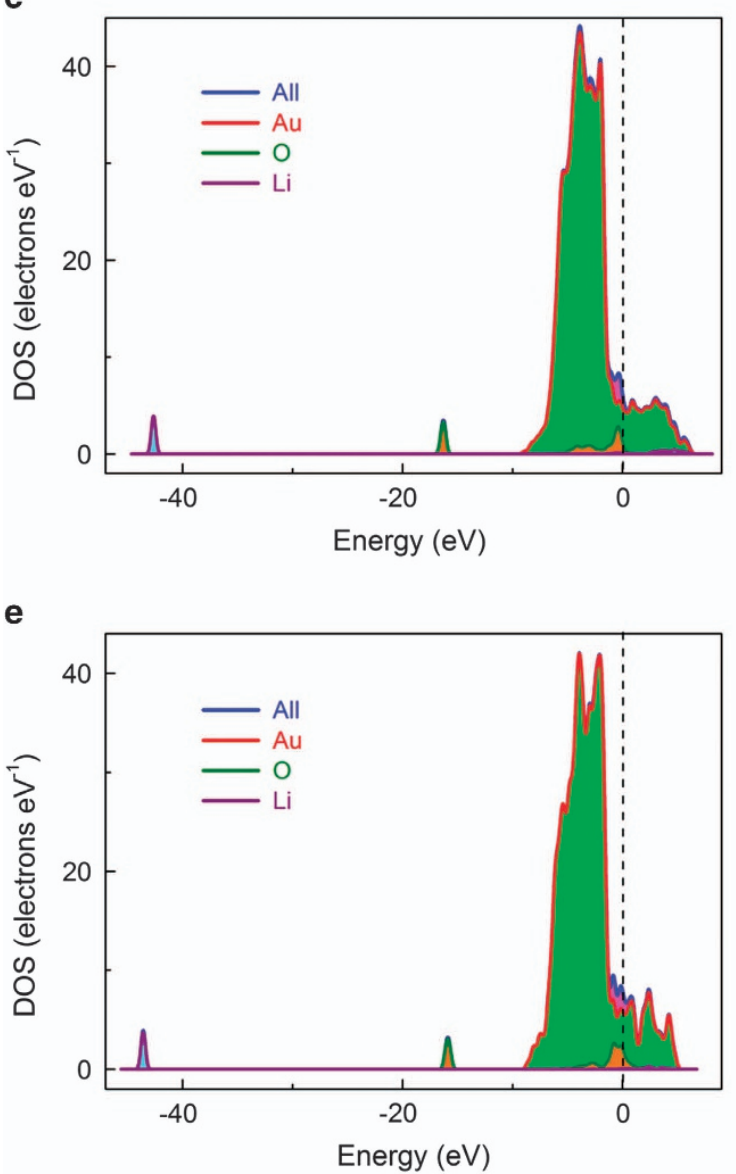

b

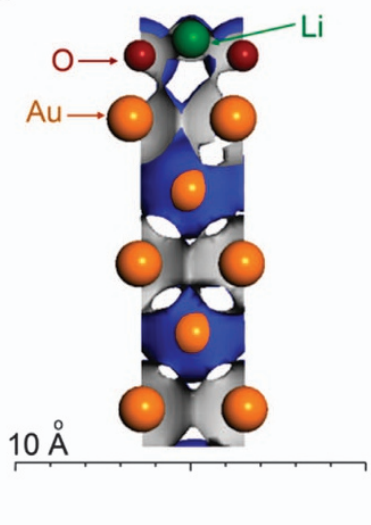

d

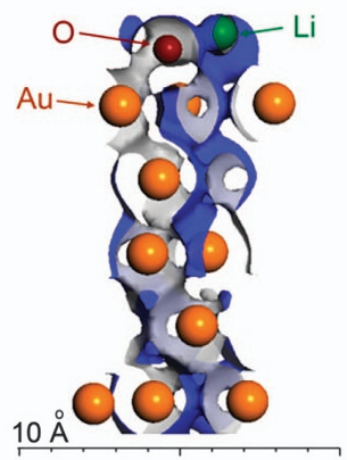

f

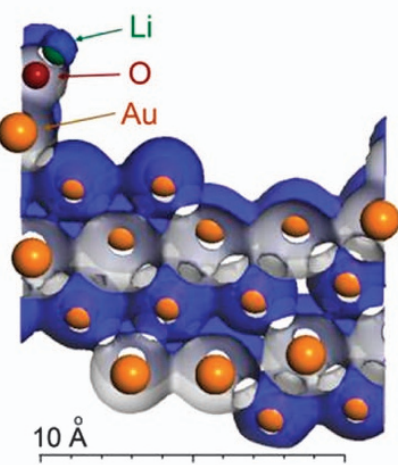

Figure 6 Density of states for the $\{100\}(\mathbf{a}),\{111\}$ (c) and $\{441\}$ (e) crystal planes interacting with $\mathrm{Li}$ and $\mathrm{O}$ atoms. (b, d and f) are their corresponding electron density plots. The vertical dashed lines in (a, c and e) denote the Fermi energy. 
T-OCT Au NCs presented the gradually improved catalytic activity toward the ORR and OER because their exposed facets ( $\{100\}$ and $\{111\})$ have lower oxygen adsorption energy, which promotes a decrease in the discharge-charge overpotential.

Furthermore, the calculated densities of states for the $\{100\},\{111\}$ and $\{441\}$ crystal planes of Au NCs clearly demonstrate their interaction with those of the $\mathrm{Li}$ and $\mathrm{O}$ atoms due to the overlapping densities of states curves (as shown in Figure 6). The corresponding electron density plots ((b), (d) and (f) in Figure 6), showing the electron distribution between each crystal plane and the $\mathrm{Li}$ and $\mathrm{O}$ atoms, confirm that the different crystal planes of Au NCs could provide varied reactive sites for the reaction between $\mathrm{Li}$ and $\mathrm{O}$ atoms. Among them, the $\{441\}$ crystal planes present the largest amount of interaction sites with $\mathrm{Li}$ and $\mathrm{O}$ atoms (Figure 6f), which can be verified by the presence of more overlapping electron orbitals between $\mathrm{Au}, \mathrm{Li}$ and $\mathrm{O}$ at the Fermi level (densities of states curve in Figure 6e), suggesting that they have the highest catalytic activity toward the $\mathrm{Li}$ and $\mathrm{O}$ reaction. The enhanced electrocatalytic activity of Au NCs with exposed high-index surfaces has also been demonstrated previously. ${ }^{14,41}$ Therefore, the TOH Au NCs@SP electrode achieved the best electrochemical performance.

Catalysts play a critical role in increasing the discharge capacity and reducing the charge and discharge overpotential. It was reported that catalyst surface area is very important to affect electrochemical performances of $\mathrm{Li}-\mathrm{O}_{2}$ battery, ${ }^{42}$ because the kinetics of most catalytic reactions are surface area dependent. ${ }^{43}$ The Super-P carbon has a high surface area, resulting in the faster reaction rates per gram of carbon and more active surface sites for $\mathrm{Li}_{2} \mathrm{O}_{2}$ deposition, which also benefit for the increase of discharge capacity. ${ }^{44}$

The homogenous distribution of catalyst nanoparticles is another reason for the improvement of catalytic effects, because the uniform $\mathrm{Au}$ NCs significantly decrease agglomeration and the small SP particles $(\sim 50 \mathrm{~nm})$ provide an efficient surface for loading catalyst nanoparticles. From Figure 5, it can be seen that even after significant $\mathrm{Li}_{2} \mathrm{O}_{2}$ deposition, the original morphology of SP is well maintained. Au NCs are clearly visible in the ex-situ TEM image (Figure 5g), which expose with sufficient active surface for catalytic reactions.

\section{CONCLUSION}

In summary, we report the synthesis of polyhedral Au NCs with different exposed crystal planes: cubic Au NCs with $\{100\}$ exposed facets, T-OCT Au NCs with $\{100\}$ and $\{110\}$ exposed facets, and TOH Au NCs with 24 high-index $\{441\}$ exposed facets. As effective cathode catalysts for the $\mathrm{Li}-\mathrm{O}_{2}$ batteries, the electrochemical testing shows that all the $\mathrm{Au}$ NCs can significantly reduce the charge overpotential via their effects on the OER and achieve high specific capacity, leading to enhanced electrochemical performances. In particular, the $\mathrm{TOH} \mathrm{Au}$ $\mathrm{NC}$ catalysts demonstrated the lowest charge overpotential $(\sim 0.9 \mathrm{~V})$ and the highest reversible capacity of about $20298 \mathrm{~mA} \mathrm{~h} \mathrm{~g}^{-1}$. From the comparison of the catalytic performances of different Au NCs, it is revealed that the essential factor in promoting the ORR and OER of $\mathrm{Au}$ NCs is the surface crystal planes. The correlation between different Au NC crystal planes and their catalytic activity was established: $\{100\}$ $<\{111\}<\{441\}$, which was verified by density function theory calculations and experimental investigations. As revealed by the exsitu XRD, SEM and TEM measurements, we also proved that polyhedral Au NC catalysts can effectively decompose the discharge product $\mathrm{Li}_{2} \mathrm{O}_{2}$, facilitating the OER, leading to a high round-trip efficiency, and present superior cycling stability. This study demonstrates that Au NCs, especially with exposed high-index facets, could be effective cathode catalysts for high performance $\mathrm{Li}-\mathrm{O}_{2}$ batteries.

\section{CONFLICT OF INTEREST}

The authors declare no conflict of interest.

\section{ACKNOWLEDGEMENTS}

This original research was proudly supported by the Commonwealth of Australia through the Automotive Australia 2020 Cooperative Research Centre (AutoCRC). The authors acknowledge use of the facilities and the assistance of Dr Gilberto Casillas at the UOW Electron Microscopy Centre. The authors thank Dr Tania Silver for critical reading.

1 Bruce, P. G., Freunberger, S. A., Hardwick, L. J. \& Tarascon, J.-M. Li-O 2 and Li-S batteries with high energy storage. Nat. Mater. 11, 19-29 (2012).

2 Whittingham, M. S. Lithium batteries and cathode materials. Chem. Rev. 104, 4271-4302 (2004).

3 Mitchell, R. R., Gallant, B. M., Thompson, C. V. \& Shao-Horn, Y. All-carbon-nanofiber electrodes for high-energy rechargeable $\mathrm{Li}^{-} \mathrm{O}_{2}$ batteries. Energy Environ. Sci. 4, 2952-2958 (2011).

$4 \mathrm{Li}, \mathrm{F}$., Zhang, T. \& Zhou, H. Challenges of non-aqueous $\mathrm{Li}^{-} \mathrm{O}_{2}$ batteries: electrolytes, catalysts, and anodes. Energy Environ. Sci. 6, 1125-1141 (2013).

5 McCloskey, B., Bethune, D., Shelby, R., Girishkumar, G. \& Luntz, A. Solvents' critical role in nonaqueous lithium-oxygen battery electrochemistry. J. Phys. Chem. Lett. 2, 1161-1166 (2011).

6 Lu, Y.-C., Kwabi, D. G., Yao, K. P. C., Harding, J. R., Zhou, J. \& Zuin, L. The discharge rate capability of rechargeable $\mathrm{Li}-\mathrm{O}_{2}$ batteries. Energy Environ. Sci. 4, 2999-3007 (2011).

7 Lu, Y.-C., Crumlin, E. J., Veith, G. M., Harding, J. R., Mutoro, E., Baggetto, L., Dudney, N. J., Liu, Z. \& Shao-Horn, Y. In situ ambient pressure X-ray photoelectron spectroscopy studies of lithium-oxygen redox reactions. Sci. Rep. 2, 715 (2012).

8 Hsieh, Y.-C., Zhang, Y., Su, D., Volkov, V., Si, R., Wu, L., Zhu, Y., An, W., Liu, P., He, P., Ye, S., Adzic, R. R. \& Wang, J. X. Ordered bilayer ruthenium-platinum core-shell nanoparticles as carbon monoxide-tolerant fuel cell catalysts. Nat. Commun 4, 2466 (2013).

9 Xu, J.-J., Wang, Z.-L., Xu, D., Zhang, L.-L. \& Zhang, X.-B. Tailoring deposition and morphology of discharge products towards high-rate and long-life lithium-oxygen batteries. Nat. Commun. 4, 2438 (2013).

10 Black, R., Lee, J. H., Adams, B., Mims, C. A. \& Nazar, L. F. The role of catalysts and peroxide oxidation in lithium-oxygen batteries. Angew. Chem. 125, 410-414 (2013).

11 Hummelshøj, J., Luntz, A. \& Nørskov, J. Theoretical evidence for low kinetic overpotentials in $\mathrm{Li}-\mathrm{O}_{2}$ electrochemistry. J. Chem. Phys. 138, 034703 (2013).

12 Tao, A. R., Habas, S. \& Yang, P. Shape control of colloidal metal nanocrystals. Small 4 , 310-325 (2008)

13 Somorjai, G. A. \& Blakely, D. Mechanism of catalysis of hydrocarbon reactions by platinum surfaces. Nature 258, 580-583 (1975).

14 Tian, N., Zhou, Z. Y., Sun, S. G., Ding, Y. \& Wang, Z. L. Synthesis of tetrahexahedral platinum nanocrystals with high-index facets and high electro-oxidation activity. Science 316, 732-735 (2007).

15 Peng, Z. Q., Freunberger, S. A., Chen, Y. H. \& Bruce, P. G. A reversible and higher-rate $\mathrm{Li}-\mathrm{O}_{2}$ battery. Science 337, 563-566 (2012).

16 Ming, T., Kou, X., Chen, H., Wang, T., Tam, H. L., Cheah, K. W., Chen, J. Y. \& Wang, J. Ordered gold nanostructure assemblies formed by droplet evaporation. Angew. Chem. 47, 9685-9690 (2008).

17 Amadon, B., Jollet, F. \& Torrent, M. Gamma and beta cerium: LDA+U calculations of ground-state parameters. Phys. Rev. B 77, 155104(155101)-155104(155110) (2008).

18 Gonze, X., Amadon, B., Anglade, P.-M., Beuken, J.-M., Bottin, F., Boulanger, P., Bruneval, F., Caliste, D., Caracas, R., Côté, M., Deutsch, T., Genovese, L., Ghosez, Ph., Giantomassi, M., Goedecker, S., Hamann, D. R., Hermet, P., Jollet, F., Jomard, G., Leroux, S., Mancini, M., Mazevet, S., Oliveira, M. J. T., Onida, G., Pouillon, Y., Rangel, T., Rignanese, G.-M., Sangalli, D., Shaltaf, R., Torrent, M., Verstraete, M. J., Zerah, G. \& Zwanziger, J. W. ABINIT: first-principles approach to material and nanosystem properties. Comput. Phys. Commun. 180, 2582-2615 (2009).

19 Perdew, J. P. \& Wang, Y. Accurate and simple analytic representation of the electrongas correlation-energy. Phys. Rev. B 45, 13244-13249 (1992).

20 Tasker, P. W. Stability of Ionic-Crystal Surfaces. J. Phys. C Solid St 12, 4977-4984 (1979).

21 Yu, Y., Zhang, Q., Liu, B. \& Lee, J. Y. Synthesis of nanocrystals with variable high-index $\mathrm{Pd}$ facets through the controlled heteroepitaxial growth of trisoctahedral Au templates. J. Am. Chem. Soc. 132, 18258-18265 (2010).

22 Tian, N., Zhou, Z.-Y. \& Sun, S.-G. Platinum metal catalysts of high-index surfaces: from single-crystal planes to electrochemically shape-controlled nanoparticles. J. Phys. Chem. C 112, 19801-19817 (2008)

23 Van Hove, M. \& Somorjai, G. A new microfacet notation for high-Miller-index surfaces of cubic materials with terrace, step and kink structures. Surf. Sci. 92, 489-518 (1980).

24 Wang, Z. L. Transmission electron microscopy of shape-controlled nanocrystals and their assemblies. J. Phys. Chem. B 104, 1153-1175 (2000).

25 Nikoobakht, B. \& El-Sayed, M. A. Preparation and growth mechanism of gold nanorods (NRs) using seed-mediated growth method. Chem. Mater. 15, 1957-1962 (2003). 
26 Johnson, C. J., Dujardin, E., Davis, S. A., Murphy, C. J. \& Mann, S. Growth and form of gold nanorods prepared by seed-mediated, surfactant-directed synthesis. J. Mater. Chem. 12, 1765-1770 (2002).

27 Sau, T. K. \& Murphy, C. J. Room temperature, high-yield synthesis of multiple shapes of gold nanoparticles in aqueous solution. J. Am. Chem. Soc. 126, 8648-8649 (2004).

28 Millstone, J. E., Wei, W., Jones, M. R., Yoo, H. \& Mirkin, C. A. lodide ions control seedmediated growth of anisotropic gold nanoparticles. Nano Lett. 8, 2526-2529 (2008).

$29 \mathrm{Ha}$, T. H., Koo, H.-J. \& Chung, B. H. Shape-controlled syntheses of gold nanoprisms and nanorods influenced by specific adsorption of halide ions. J. Phys. Chem. C 111, 1123-1130 (2007).

30 Grzelczak, M., Pérez-Juste, J., Mulvaney, P. \& Liz-Marzán, L. M. Shape control in gold nanoparticle synthesis. Chem. Soc. Rev. 37, 1783-1791 (2008).

31 Murphy, C. J., Sau, T. K., Gole, A. M., Orendorff, C. J., Gao, J., Gou, L., Hunyadi, S. E. \& Li, T. Anisotropic metal nanoparticles: synthesis, assembly, and optical applications. J. Phys. Chem. B 109, 13857-13870 (2005).

32 Yu, Y., Zhang, Q., Lu, X. \& Lee, J. Y. Seed-mediated synthesis of monodisperse concave trisoctahedral gold nanocrystals with controllable sizes. J. Phys. Chem. C 114 11119-11126 (2010)

33 Oh, S. H., Black, R., Pomerantseva, E., Lee, J.-H. \& Nazar, L. F. Synthesis of a metallic mesoporous pyrochlore as a catalyst for lithium $-\mathrm{O}_{2}$ batteries. Nat. Chem 4, 1004-1010 (2012).

34 Laoire, C. O., Mukerjee, S., Abraham, K., Plichta, E. J. \& Hendrickson, M. A. Elucidating the mechanism of oxygen reduction for lithium-air battery applications. J. Phys. Chem. C 113, 20127-20134 (2009).

35 Tian, N., Zhou, Z. Y. \& Sun, S. G. Electrochemical preparation of Pd nanorods with high-index facets. Chem. Commun. 12, 1502-1504 (2009).

36 Xie, X., Li, Y., Liu, Z.-Q., Haruta, M. \& Shen, W. Low-temperature oxidation of CO catalysed by $\mathrm{Co}_{3} \mathrm{O}_{4}$ nanorods. Nature 458, 746-749 (2009).

37 Han, X. G., He, H. Z., Kuang, Q., Zhou, X., Zhang, X. H., Xu, T., Xie, Z. X. \& Zheng, L. S Controlling morphologies and tuning the related properties of nano/microstructured $\mathrm{ZnO}$ crystallites. J.Phys. Chem. C 113, 584-589 (2009).
38 Somorjai, G. A. Chemistry in two dimensions: surfaces. Chemistry in Two Dimensions: Surfaces (1981).

39 Lebedeva, N. P. Koper, M. T. M., Feliu, J. M. \& van Santen, R. A. Role of crystalline defects in electrocatalysis: mechanism and kinetics of $\mathrm{CO}$ adlayer oxidation on stepped platinum electrodes. J. Phys. Chem. B 106, 12938-12947 (2002).

$40 \mathrm{Lu}$, Y.-C., Gasteiger, H. A. \& Shao-Horn, Y. Catalytic activity trends of oxygen reduction reaction for nonaqueous Li-air batteries. J. Am. Chem. Soc. 133, 19048-19051 (2011).

$41 \mathrm{Ma}$, Y., Kuang, Q., Jiang, Z., Xie, Z., Huang, R. \& Zheng, L. Synthesis of trisoctahedra gold nanocrystals with exposed high-index facets by a facile chemical method. Angew. Chem. 47, 8901-8904 (2008).

42 Aurélie, D., Bao, J. L., Armstrong, G. \& Bruce, P. G. An $\mathrm{O}_{2}$ cathode for rechargeable lithium batteries: the effect of a catalyst. J. Power Sources 174, 1177-1182 (2007).

43 Oh, S. H. \& Nazar, L. F. Oxide catalysts for rechargeable high-capacity Li-02 batteries. Adv. Energy Mater 2, 903-910 (2012).

44 Lu, Y. C., Gasteiger, H. A., Parent, M. C., Chiloyan, V. \& Yang, S.-H. The influence of catalysts on discharge and charge voltages of rechargeable Li-Oxygen batteries. Electrochem. Solid-State Lett. 13, A69-A72 (2010).

(1) (2) (2) This work is licensed under a Creative Commons Attribution-NonCommercial-ShareAlike $\quad 4.0$ International License. The images or other third party material in this article are included in the article's Creative Commons license, unless indicated otherwise in the credit line; if the material is not included under the Creative Commons license, users will need to obtain permission from the license holder to reproduce the material. To view a copy of this license, visit http://creativecommons.org/licenses/ by-nc-sa/4.0/

Supplementary Information accompanies the paper on the NPG Asia Materials website (http://www.nature.com/am) 